Document downloaded from:

http://hdl.handle.net/10251/98042

This paper must be cited as:

Vendrell Criado, V.; Rodríguez Muñiz, GM.; Lhiaubet ., VL.; Cuquerella Alabort, MC.; Miranda Alonso, MÁ. (2016). The (6-4) Dimeric Lesion as a DNA Photosensitizer. ChemPhysChem (Online). 17(13):1979-1982. doi:10.1002/cphc.201600154

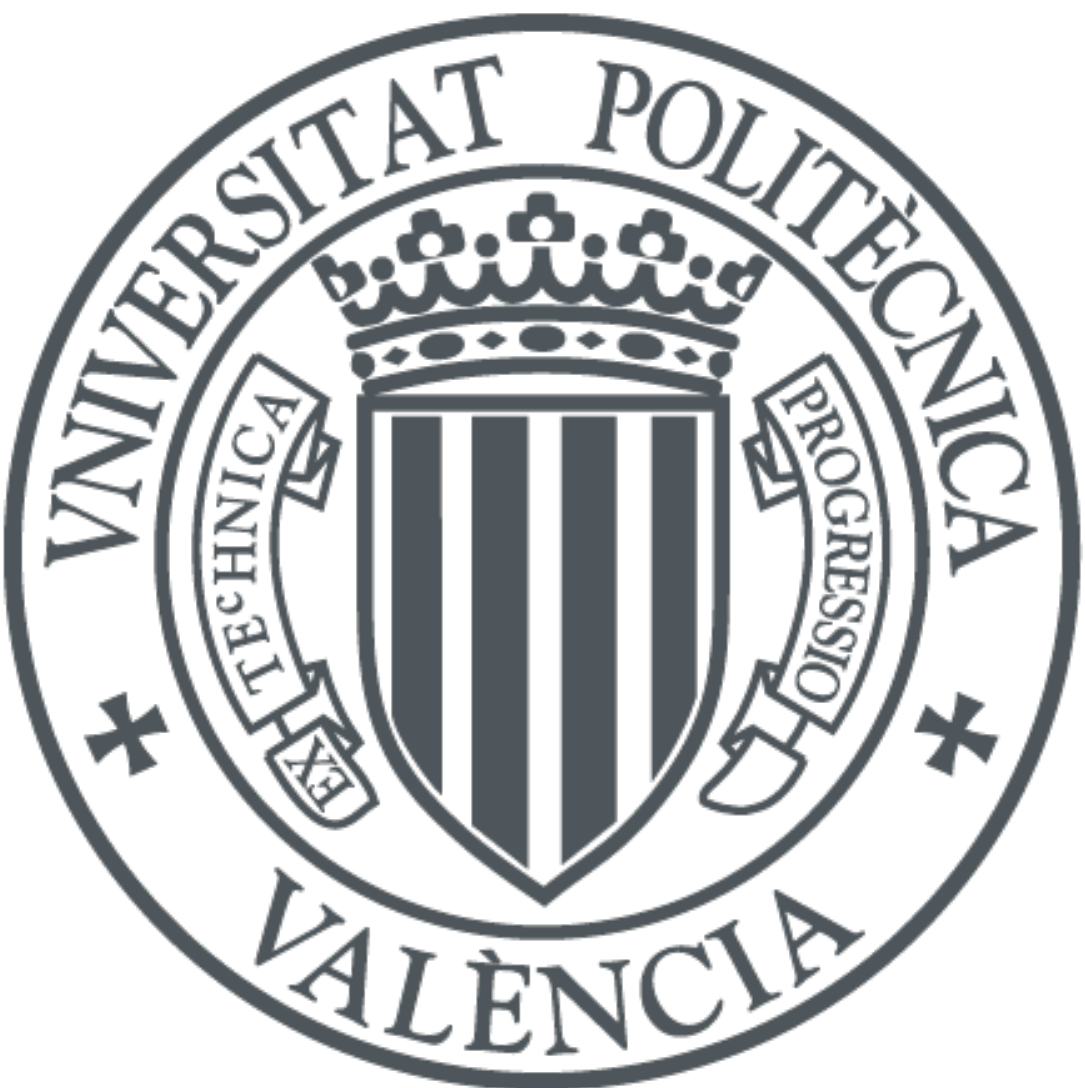

The final publication is available at

http://dx.doi.org/10.1002/cphc.201600154

Copyright John Wiley \& Sons

Additional Information 


\title{
The (6-4) Dimeric Lesion as a DNA Photosensitizer
}

Victoria Vendrell-Criado, Gemma M. Rodríguez-Muñiz, Virginie Lhiaubet-Vallet, M. Consuelo Cuquerella* and Miguel A. Miranda*

\begin{abstract}
Based on our previous work on the photophysical properties of the 5-methyl-2-pyrimidone (Pyo) chromophore, we have now extended our studies to the photobehavior of the dimeric (6-4) thymine photoproducts (6-4 PP) to evaluate their capability to act as an instrinsic DNA photosensitizers. The lesion presents significant absorption in the UVB/UVA region, weak fluorescence emission, a singlet excited state energy of ca. $351 \mathrm{~kJ} \mathrm{~mol}^{-1}$, and a triplet energy of $297 \mathrm{~kJ} \mathrm{~mol}^{-1}$. Its triplet transient absorption was observed with maximum at 420-440 nm, a lifetime of ca. $7 \mu \mathrm{s}$, and a high formation quantum yield $\Phi_{\text {ISC }}=0.86$. This species is efficiently quenched by thymidine. Its DNA photosensitizing properties have been demonstrated by a series of experiments run on a pBR322 plasmid. It is observed that the lesion photoinduces both single strand breaks and cyclobutane thymine dimers. Altogether, these results show that, substitution of the pyrimidone ring at $\mathrm{C} 4$ by 5 -hydroxy-5,6-dihydrothymine does not cancel out the photosensitization properties of the chromophore.
\end{abstract}

\section{Introduction}

The correlations established between photoinduced damage to DNA and skin cancer have promoted an intense research activity to establish the mechanisms that govern the formation and repair of DNA photolesions. The damage can be produced by direct UVB ( 290 to $320 \mathrm{~nm}$ ) irradiation but also upon UVA ( 320 to $400 \mathrm{~nm}$ ) light absorption by a chromophore in the vicinity of the double helix. This latter process, known as photosensitization, may initiate triplet-triplet energy transfer.[1] The triplet excited state of pyrimidine bases leads to cyclobutane dimers (CPDs,[2] Chart 1), although the efficiency of this process may be low.[1e, 3] Typically, photosensitization is triggered by xenobiotics, but also by endogenous compounds. In this context, our recent investigation has suggested that (6-4) photoproducts (6-4 PPs, Chart 1), resulting from direct UVB

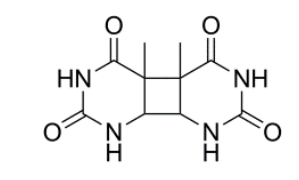

Thymine cyclobutane dimers (CPD)

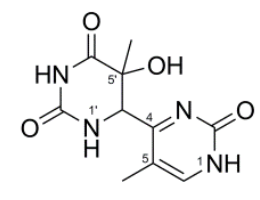

(6-4) Thymine photoproducts (6-4 PP)

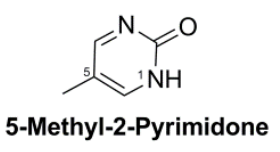

Chart 1. Chemical structures of thymine CPD, 6-4 PP and the Pyo moiety.

DNA irradiation, may in turn act as effective endogenous photosensitizers, since their substructure 5-methyl-2-pyrimidone (Pyo) mediates photogeneration of CPD and single strand 
breaks (ssb) in DNA.[4] This is supported by the facts that Pyo (i) is responsible for the UVA absorption of the lesion, (ii) has a triplet excited state energy higher than that of thymine in DNA and (iii) may behave as type I and II photosensitizer by hydrogen abstraction or generation of oxidizing species like $\mathrm{OH}^{*}$ or ${ }^{1} \mathrm{O}_{2}$. Indeed, recent theoretical calculations are consistent with this behavior.[4b, 5] However, the presence of the 5-hydroxy-5,6-dihydrothymine substitution at C4 of the pyrimidone ring could modulate the chemical or physical properties of the chromophore and as a consequence, the dimeric (6-4) photolesion might not behave in the same way as the Pyo substructure.[6] As a matter of fact, the photophysical properties of the chromophore integrated in more complex systems like "pure" or bioisosteric dinucleotides, show wide variations according to the literature: $[4 a, 7]$ its fluorescence $\lambda_{\max }$ encompasses from 380 to 400 $\mathrm{nm}$, its quantum yield from 0.01 to 0.2 and its singlet energy from 370 to $432 \mathrm{~kJ} \mathrm{~mol}^{-1}$.[7] Moreover, the Pyo triplet lifetime $\left(\tau_{\top}\right)$ is within the microsecond range,[4a] while it appears to decrease down to hundreds of nanoseconds when the chromophore is included in bioisosteric dinucleotides.[7c] In any case, such triplet lifetimes would be compatible with oxygen quenching, to produce singlet oxygen. However, little is known about the intersystem crossing quantum yield $\left(\Phi_{I S C}\right)$ or the triplet energy value $\left(E_{T}\right)$, which are key parameters to anticipate the DNA photosensitizing potential. The available estimates point to an inefficient population of the triplet excited state with $\Phi_{\text {Isc }}$ values as low as 0.02-0.10.[7c]

Based on our previous work on the photophysical properties of Pyo, we have now extended our studies to the photobehavior of the dimeric (6-4) thymine photoproducts (6-4 PP), which contain the Pyo chromophore to evaluate its capability to act as an endogeneos DNA photosensitizer. The obtained data reveal that 6-4 PP can indeed mediate DNA photodamage, due to the unexpected high values of $\tau_{T}, \Phi_{\text {Isc }}$ and ET (Table 1). As a consequence, the 6-4 PP primary lesion can act as a Trojan horse, leading to secondary CPD or oxidative damage in its neighborhood. This may be relevant in connection with the occurrence of "tandem" or clustered lesions, where several DNA modifications are formed within a few base pairs.

\section{Results and Discussion}

The attention was first focused on the singlet excited state properties of 6-4 PP in PBS solution. As shown in Figure 1, the absorption spectrum was characterized by a band in the UVB/UVA region with a maximum peaking at $314 \mathrm{~nm}$. This long wavelength absorption is important, because it extends the range of interaction with solar radiation. The fluorescence emission was centered at $376 \mathrm{~nm}$ (Figure 1), and its quantum yield was ca. 0.09 (standard: carprofen, Фst= 0.068).[8] A singlet excited state energy (ES) of ca. $351 \mathrm{~kJ} \mathrm{~mol}^{-1}$ was determined from the intersection between the normalized emission and excitation spectra.

Next, phosphorescence experiments were performed at 77K to characterize the 6-4 PP triplet excited state ( ${ }^{3} 6-4$ PP*). The spectrum showed a broad band centered at $441 \mathrm{~nm}$ (Figure 1). Due to the absence of vibrational structure, $E_{T}$ was obtained from the wavelength corresponding to $10-20 \%$ of the emission intensity. Interestingly, this value (ET= $297 \mathrm{~kJ} \mathrm{~mol}^{-1}$ ) was somewhat higher than that previously described for Pyo.[4a] The triplet-triplet transient absorption spectrum obtained using $308 \mathrm{~nm}$-laser flash photolysis exhibited a broad band from 320 to 500 $\mathrm{nm}$, with maximum at 420-440 $\mathrm{nm}$ (Figure 2). This species, with $\tau_{\top}=7.2 \mu \mathrm{s}$, was efficiently quenched by oxygen with a $\mathrm{kq}(\mathrm{O} 2)=2.7109 \mathrm{M}^{-1} \mathrm{~s}^{-1}$ (Figure 2, inset). An efficient triplet yield $\left(\Phi_{\text {ISC }}=0.86\right)$ was determined by means of the comparative method, using the benzophenone triplet-triplet transient absorption as standard (see Experimental Section). Overall, these data (summarized in Table 1 ) indicate that substitution of the pyrimidone chromophore at $\mathrm{C} 4$ by 5 - 
hydroxy-5,6-dihydrothymine does not cancel out the photosensitization properties of the chromophore.

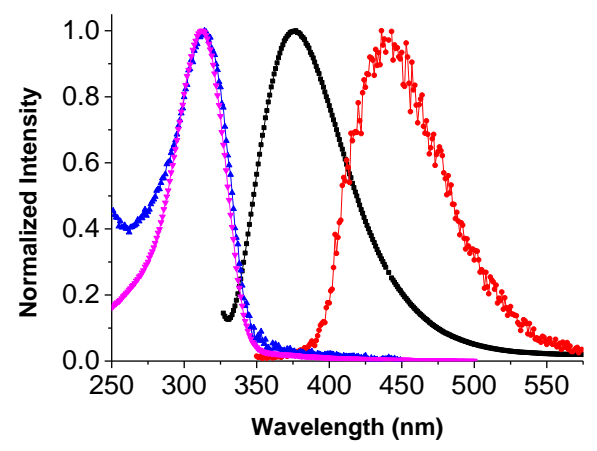

Figure 1. Absorption (blue) and emission (black) spectra of 6-4 PP in phosphate buffer at room temperature or in $\mathrm{EtOH}(77 \mathrm{~K})$ for phosphorescence (red). Pyo absorption has also been included (pink trace).

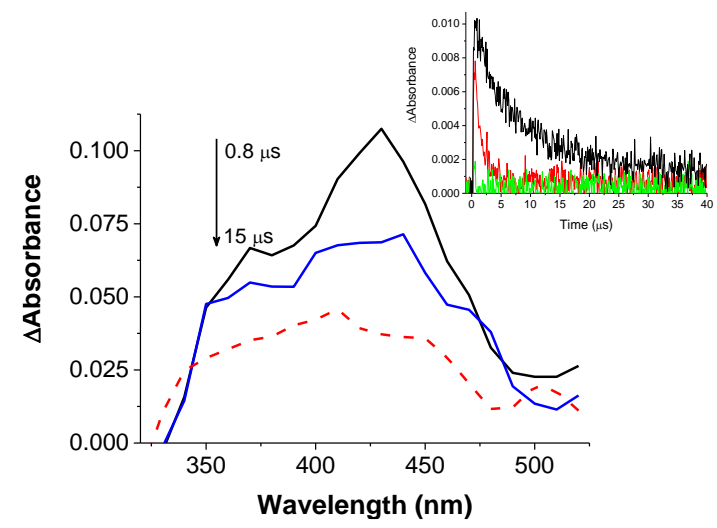

Figure 2. Transient absorption spectra of a $\mathrm{N}_{2} \mathrm{O}$-bubbled phosphate buffer solution of 6-4 PP at different times after the $308 \mathrm{~nm}$ laser pulse. Inset: Decay monitored at $420 \mathrm{~nm}$ under $\mathrm{N}_{2} \mathrm{O}$ (black), air (red) or $\mathrm{O} 2$ (green) conditions.

In this context, the $E_{T}$ value of 6-4 PP makes this lesion a good energy donor for the generation of cyclobutane thymine dimers $(\mathrm{T}<>\mathrm{T})$ through a triplet-triplet energy transfer process from ${ }^{3} 6$ $4 \mathrm{PP} *$ to thymine triplet excited state. This was confirmed by quenching of ${ }^{3} 6-4 \mathrm{PP} *$ by thymidine (Thd). As shown in Figure 3 , the $\tau_{\top}$ of ${ }^{3} 6-4$ PP* monitored at $420 \mathrm{~nm}$ was progressively shortened in the presence of increasing amounts of Thd. A quenching rate constant $k_{q}$ (Thd) of $2108 \mathrm{M}^{-1} \mathrm{~s}$. 1 was obtained from the Stern-Volmer plot (Figure 3, inset).

Interestingly, this value is one order of magnitude higher than that of Pyo (Table 1), in agreement with the relative higher ET values and with the influence of the donor-acceptor gap on the energy transfer rate according to Sandros' equation.[9]

Having determined the key photophysical properties of 6-4 PP, which allowed anticipating a clear DNA photosensitizing potential, a step forward was to run a series of experiments on a pBR322 plasmid using agarose gel electrophoresis. Briefly, native supercoiled form I was converted into the circular form II after a single strand break (ssb). As these two forms exhibit different electrophoretic mobility, their quantification was achieved by densitometry of the gel 
bands (Figure 4). Experiments were complemented by the use of a specific enzyme, the T4 endonuclease $\mathrm{V}$ (Endo $\mathrm{V}$ ), to reveal $\mathrm{T}<>\mathrm{T}$ lesions that cannot be observed directly as ssb. Incubation with

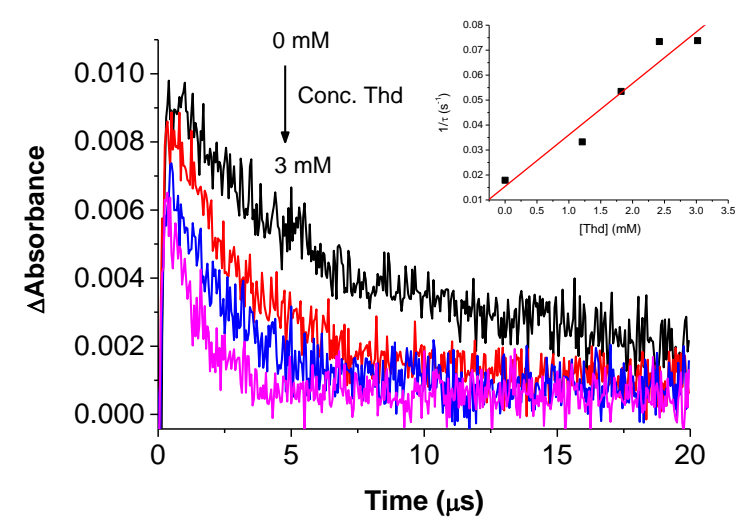

Figure 3. Quenching of 6-4 PP triplet excited state by Thd (from 0 to $3 \mathrm{mM}$ ). Decays monitored at 420 $\mathrm{nm}$ under $\mathrm{N}_{2} \mathrm{O}$ conditions. Inset: Corresponding Stern-Volmer plot.

\section{6-4 PP Pyo}

\begin{tabular}{|c|c|c|c|}
\hline$\lambda$ Abs (nm) & 314 & 310 & \\
\hline$\lambda$ Fluo (nm) & 376 & 380 & \\
\hline ФFluo & 0.094 & 0.084 & \\
\hline$\lambda$ Phospho (nm) & ) 441 & 453 & \\
\hline $\mathrm{E}_{\mathrm{S}}(\mathrm{kJ} \mathrm{mol}-1)$ & 351 & 351 & \\
\hline $\mathrm{E}_{\mathrm{T}}(\mathrm{kJ} \mathrm{mol}-1)$ & 297 & 291 & \\
\hline$\lambda_{\mathrm{T}-\mathrm{T}}(\mathrm{nm})$ & 420 & 420 & \\
\hline$\tau_{\top}(\mu s)$ & 7.2 & 9.7 & \\
\hline$\Phi_{\text {ISC }}$ & 0.86 & 0.75 & \\
\hline $\mathrm{kq}\left(\mathrm{O}_{2}\right)\left(\mathrm{M}^{-1} \mathrm{~s}^{-1}\right)$ & 2.7510 & & $2.7010^{9}$ \\
\hline $\mathrm{kq}(\mathrm{Thd})\left(\mathrm{M}^{-1} \mathrm{~s}^{-1}\right.$ & $-1) 210^{8}$ & & $1.610^{7}$ \\
\hline
\end{tabular}

Table 1. Photophysical properties of 6-4 PP compared to Pyo

Endo $V$ resulted in the formation of $s s b$ at the lesion site, and thus induced an increase of circular form II. Moreover, direct ssb and $\mathrm{T}<>\mathrm{T}$ formation was studied as a function of 6-4 PP concentration (from $38 \mu \mathrm{M}$ to $304 \mu \mathrm{M}$ ), pBR322 being maintained constant at $38 \mu \mathrm{M}$ in base pair (9 nM). As shown in Figure 4A, both ssb and T<>T increased with 6-4 PP concentration, at 
least until a ratio of 8/1 (6-4 PP/DNA). Thus, this value represents a good balance between high $\mathrm{T}<>\mathrm{T}$ formation and low direct ssb. Hence, a time-dependent irradiation was performed under these conditions. As shown in Figure 4B, both direct ssb and Endo $V$ mediated cleavage increased along the irradiation time, with form II reaching after $20 \mathrm{~min}$ a value of $5 \%$ and $18 \%$, respectively.
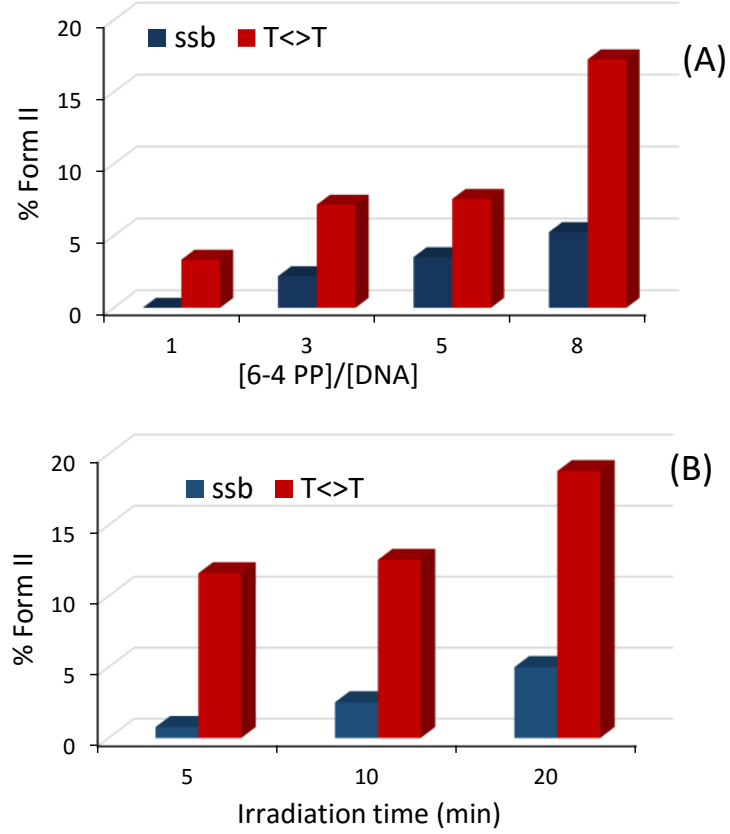

Figure 4. (A) Single strand break formation (ssb) and cyclobutane thymine dimers ( $T<>T$ ) as a function of [6-4 PP]/[DNA base pair] ratio. Mixtures of pBR322 (38 $\mu \mathrm{M}$ in base pair) and 6-4 PP (from 38 to $304 \mu \mathrm{M}$ ) irradiated for $20 \mathrm{~min}$ at $355 \mathrm{~nm}$. (B) Photosensitization of ssb and T<>T by 6-4 PP as a function of irradiation time. Mixture of pBR322 (38 $\mu \mathrm{M}$ in base pair) and 6-4 PP $(304 \mu \mathrm{M})$ irradiated in the UVA and incubated or not with Endo V. For the sake of clarity, the values of ssb and $\mathrm{T}<>\mathrm{T}$ for DNA irradiated alone were subtracted (full data are available in the Supplementary file).

\section{Conclusions}

In summary, the (6-4) dimeric photolesion, upon absorption of UVB/UVA light, gives rise to a sufficiently long-lived triplet excited state with a high intersystem crossing quantum yield. These features as well as the relative high triplet energy are responsible for the fact that substitution of pyrimidone chromophore at C4 by 5-hydroxy-5,6-dihydrothymine does not cancel out the photosensitization properties of the chromophore. Consequently, the primary lesion may lead to sensitized CPD formation in its neighborhood, resulting in an enhanced biological risk that may have been overlooked.

\section{Experimental Section}

Triplet excited state of 6-4 PP as sensitizer of Thd dimerization in DNA. The 6-4 PP was synthesized following an established procedure.[10] Samples containing $5 \mu \mathrm{L}(9 \mathrm{nM}, 38 \mu \mathrm{M}$ in base pair) of supercoiled circular DNA (pBR322, 4361 base pair) in absence or presence of 6-4 PP (from 38 to $304 \mu \mathrm{M}$ ) were employed in electrophoresis experiment. The samples were irradiated using a multilamp photoreactor with lamps emitting in the $300-400 \mathrm{~nm}$ range with a 
maximum at $350 \mathrm{~nm}$. Next, they were incubated for $1 \mathrm{~h}$ at $37 \stackrel{\circ}{\circ}$ with an excess of T4 endonuclease $\mathrm{V}$. The samples were loaded on a $0.8 \%$ agarose gel containing ethidium bromide. After electrophoresis, the relative abundance of supercoiled DNA (form I) and relaxed DNA (form II) was quantified by densitometry. An error of \pm 1 and $\pm 5 \%$ was determined for experiments of ssb and $\mathrm{T}<>\mathrm{T}$, respectively.

Spectroscopic measurements. All the spectroscopic measurements were performed at room temperature using quartz cells of $1 \mathrm{~cm}$ optical path. The fluorescence of the samples was registered after adjusting their absorbance to ca. 0.1 at the excitation wavelength $\left(\lambda_{\text {exc }}=313\right.$ $\mathrm{nm}$ ). On the other hand, 6-4 PP was dissolved in ethanol, placed in a quartz tube and cooled at $77 \mathrm{~K}$ to obtain its phosphorescence spectrum.

Laser flash photolysis (LFP) was run using a pulsed Xe/HCl Excimer Laser $\left(\lambda_{\text {exc }}=308 \mathrm{~nm}\right.$ ) or a $\mathrm{Nd}$ :YAG laser $\left(\lambda_{\text {exc }}=355 \mathrm{~nm}\right.$ ). The single pulses were ca. $10 \mathrm{~ns}$ duration. A pulsed Xe lamp was employed as detecting light source. The LFP apparatus consisted of the pulsed laser, the Xe lamp, a monochromator, and a photomultiplier made up of a tube, housing, and power supply. The output signal from the oscilloscope was transferred to a personal computer.

The transient absorption spectrum of 6-4 PP in PBS was obtained after direct excitation at 308 $\mathrm{nm}$. The samples were purged with $\mathrm{N}_{2} \mathrm{O}$ and their absorbance at the excitation wavelength adjusted to ca. 0.3 .

Thymidine was used as quencher for the triplet states of 6-4 PP. The experiment was carried out adding increasing amounts of the nucleoside (from $0 \mathrm{mM}$ to $3 \mathrm{mM}$ ) to a solution of 6-4 PP, and the decays were monitored at $420 \mathrm{~nm}$.

The molar absorption coefficient of ${ }^{3} \mathrm{Pyo} *$ and ${ }^{3} 6-4 \mathrm{PP} *\left({ }^{3} \mathrm{X} *\right.$ in eq. 1 ) was obtained by the energy transfer method being xanthone the energy donor. Deaerated solutions of xanthone $\left(A_{355}=0.3\right)$ were prepared and Pyo was added. Under these conditions, Pyo or 6-4 PP is able to quench more that $95 \%$ of the xanthone triplet excited state (3Xan*). Thus, $\varepsilon_{\mathrm{T}}\left({ }^{3} X^{*}(420 \mathrm{~nm})\right)$ was calculated using eq. (1):

$$
\varepsilon_{\mathrm{T}}\left({ }^{3} \mathrm{X}^{*}(420 \mathrm{~nm})=\frac{\varepsilon_{\mathrm{T}}\left({ }^{3} \mathrm{Xan}^{*}(605 \mathrm{~nm})\right) \times \Delta \mathrm{A}\left({ }^{3} \mathrm{X}^{*}(420 \mathrm{~nm})\right.}{\Delta \mathrm{A}\left({ }^{3} \mathrm{Xan}^{*}(605 \mathrm{~nm})\right)}\right.
$$

where $\Delta \mathrm{A}\left({ }^{3} \mathrm{X}(420 \mathrm{~nm})\right)$ refers to the transient absorbance of ${ }^{3} \mathrm{Pyo}{ }^{*}$ or ${ }^{3} 6-4 \mathrm{PP} *$ at $420 \mathrm{~nm}$ at the end of the reaction, $\triangle \mathrm{A}\left({ }^{3} \mathrm{Xan}(605 \mathrm{~nm})\right)$ to the transient absorption of xanthone at the beginning of the reaction. The molar absorption coefficient of ${ }^{3} \mathrm{Xan}^{*}$ at $605 \mathrm{~nm}, \varepsilon\left({ }^{3} \mathrm{Xan}^{*}(605 \mathrm{~nm})\right)$, was taken to be $6480 \mathrm{M}^{-1} \mathrm{~cm}^{-1}$.[11] The intersystem crossing quantum yields ( $\phi_{\mathrm{Isc}}$ ) were estimated by the comparative method, determining the transient intensities of isoabsorptive acetonitrile solutions of the substrate (Pyo or 6-4 PP) and benzophenone (BP) used as standard. Thus, $\Phi_{\text {ISC }}$ was obtained by application of eq (2):

$$
\begin{gathered}
\Phi_{I S C}\left({ }^{3} \mathrm{X}^{*}(420 \mathrm{~nm})\right) x \varepsilon\left({ }^{3} \mathrm{X}^{*}(420 \mathrm{~nm})\right)= \\
=\Phi_{I S C}\left({ }^{3} \mathrm{BP}^{*}(530 \mathrm{~nm})\right) x \varepsilon\left({ }^{3} B P^{*}(530 \mathrm{~nm})\right) x \frac{\Delta A(X 420 \mathrm{~nm})}{\Delta A(B P 530 \mathrm{~nm})}
\end{gathered}
$$


where $\triangle A\left({ }_{3} X^{*}\right)$ refers to the transient absorbance of Pyo or 6-4 PP triplet at $420 \mathrm{~nm}$ under $\mathrm{N}_{2} \mathrm{O}$ atmosphere, while $\triangle \mathrm{A}\left(3 \mathrm{BP}^{*}(520 \mathrm{~nm})\right)$ refers to the absorbance of ${ }^{3} \mathrm{BP} *$ at $520 \mathrm{~nm}$. The $\mathrm{BP}$ triplet molar absorption coefficient and quantum yield in acetonitrile were taken to be $\varepsilon$ ( $^{3} \mathrm{BP} *$ $(520 \mathrm{~nm}))=6500 \mathrm{M}^{-1} \mathrm{~cm}^{-1}$ and $\Phi_{\mathrm{ISC}}(\mathrm{BP})=1$, respectively.

\section{Acknowledgements ((optional))}

Spanish Government (CTQ2015-70164-P, RIRAAF RETICS RD12/0013/0009, Prometeo II program, Severo Ochoa program/SEV-2012-0267 and JAE-Predoc 2011-00740 to V. V.-C.) is gratefully acknowledged

Keywords: cyclobutane pyrimidine dimers $\bullet$ DNA damage $\bullet$ photochemistry $\bullet$ pyrimidone $\bullet$ triplet excited states

[1] a) T. Douki, in CRC Handbook of Organic Photochemistry and Photobiology, Vol. 1, 3rd ed. (Eds.: A. Griesbeck, M. Oelgemöller, F. Ghetti), CRC Press, Boca Raton, FL, 2012, pp. 13491392; b) R. Tyrrell, E. Sage, in CRC Handbook of Organic Photochemistry and Photobiology, Vol. 1, 3rd ed. (Eds.: A. Griesbeck, M. Oelgemöller, F. Ghetti), CRC Press, Boca Raton, FL, 2012, pp. 1393-1434; c) M. C. Cuquerella, V. Lhiaubet-Vallet, J. Cadet, M. A. Miranda, Acc. Chem. Res. 2012, 45, 1558-1570; d) T. Delatour, T. Douki, C. D'Ham, J. Cadet, J. Photochem. Photobiol. B: Biol. 1998, 44, 191-198; e) S. Premi, S. Wallisch, C. M. Mano, A. B. Weiner, A. Bacchiocchi, K. Wakamatsu, E. J. H. Bechara, R. Halaban, T. Douki, D. E. Brash, Science 2015, 347, 842-847.

[2] The full chemical names for thymine cyclobutane dimers and 6-4 PPs are 4a, 2-d:4,3d']dipyrimidine-2,4,5,7(3H,4aH,4bH,6H)-tetraone and 5-hydroxy-5-methyl-6-(5-methyl-2-oxo1,2-dihydropyrimidin-4-yl)dihydropyrimidine-2,4(1H,3H)-dione, respectively.

[3] a) G. T. Wondrak, M. K. Jacobson, E. L. Jacobson, Photochem. Photobiol. Sci. 2006, 5, 215-237; b) B. Epe, Photochem. Photobiol. Sci. 2012, 11, 98-106; c) J. Cadet, T. Douki, J.-L. Ravanat, P. Di Mascio, Photochem. Photobiol. Sci. 2009, 8, 903-911; d) F. P. Noonan, M. R. Zaidi, A. Wolnicka-Glubisz, M. R. Anver, J. Bahn, A. Wielgus, J. Cadet, T. Douki, S. Mouret, M. A. Tucker, A. Popratiloff, G. Merlino, E. C. De Fabo, Nat Commun 2012, 3, 884; e) L. Liu, B. M. Pilles, J. Gontcharov, D. B. Bucher, W. Zinth, J. Phys. Chem. B 2016, 120, 292-298.

[4] a) V. Vendrell-Criado, G. M. Rodríguez-Muñiz, M. C. Cuquerella, V. Lhiaubet-Vallet, M. A. Miranda, Angew. Chem. Int. Ed. 2013, 52, 6476; b) M. Micheel, C. Torres Ziegenbein, P. Gilch, G. Ryseck, Photochem. Photobiol. Sci. 2015, 14, 1598-1606; c) H.-A. Wagenknecht, ChemPhysChem 2013, 14, 3197-3198.

[5] E. Bignon, H. Gattuso, C. Morell, E. Dumont, A. Monari, Chem. Eur. J. 2015, 21, 1150911516.

[6] J. Yamamoto, Y. Tanaka, K. Hitomi, E. D. Getzoff, S. Iwai, Nucleic Acids Symposium Series 2007, 51, 79-80.

[7] a) J. Blais, T. Douki, P. Vigny, J. Cadet, Photochem. Photobiol. 1994, 59, 402-404; b) W. Hauswirth, S. Y. Wang, Biochem. Biophys. Res. Commun. 1973, 51, 819-826; c) B. P. Fingerhut, T. T. Herzog, G. Ryseck, K. Haiser, F. F. Graupner, K. Heil, P. Gilch, W. J. Schreier, T. Carell, R. d. Vivie-Riedle, W. Zinth, New J. Phys. 2012, 14, 065006.

[8] F. Bosca, S. Encinas, P. F. Heelis, M. A. Miranda, Chem. Res. Toxicol. 1997, 10, 820-827. 
[9] a) M. C. Cuquerella, V. Lhiaubet-Vallet, F. Bosca, M. A. Miranda, Chem. Sci. 2011, 2, 1219-1232; b) K. Sandros, Acta Chem. Scand. 1964, 18, 2355-2374.

[10] a) L. M. Kundu, L. T. Burgdorf, O. Kleiner, A. Batschauer, T. Carell, ChemBioChem 2002, 3, 1053-1060; b) J. Butenandt, A. P. M. Eker, T. Carell, Chem. Eur. J. 1998, 4, 642-654.

[11] S. L. Murov, Handbook of Photochemistry, Marcel Dekker Inc., New York, 1973. 